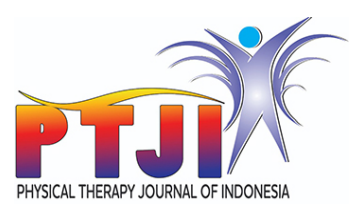

\title{
The Effectiveness of Gymnastic Respiratory Muscle Stretch and Buteyko Breathing Exercise on Peak Expiratory Flows in Older Population
}

\author{
Mahfud Hidayat ${ }^{1 *}$, Ali Multazam
}

\begin{abstract}
Introduction: Elderly is a period of life characterized by changes in function and a decrease in social life so that result in changes in muscle tissue including the respiratory system. Respiratory function in older population will decrease due to age and caused many problems. The purpose of this study was to find out the combination of respiratory muscles stretch gymnastic with buteyko breathing exercises to increase the peak expiratory flow in the elderly.

Methods: The study design is an analytical experimental method with quasi-experimental pre-test and post-test two groups design, the population in the study in Sumbersekar Village that met the

divided into experimental group and control group. Experiment group consisted of 30 samples and the control group consisted of 26 samples. Research data were analyzed by Wilcoxon Signed Rank Test.

Results: The results of this study before and after intervention are $p=0,000$ and $\mathrm{H}_{1}$ accept. The interpretation of this results is there is an effect of the combination of gymnastic respiratory muscle stretch with buteyko breathing exercises in older population.

Conclusion: There is an effect of gymnastic respiratory muscle stretch with buteyko breathing exercise in older population.
\end{abstract} inclusion criteria for three weeks. Sample in this study is 56 samples
'Physiotherapy Department, Universitas Muhammadiyah Malang

*Corresponding author: Mahfud Hidayat; Physiotherapy Department, Universitas Muhammadiyah Malang; mahfud.hidayat76@gmail.com

Received : 2020-02-03 Accepted : 2020-04-02 Published: 2020-05-15

Keywords: buteyko breathing exercise, olderly, gymnastic respiratory muscle stretch, peak expiratory flows

Cite this Article: Hidayat, M., Multazam, A. 2020. The Effectiveness of Gymnastic Respiratory Muscle Stretch and Buteyko Breathing Exercise on Peak Expiratory Flows in Older Population. Physical Therapy Journal of Indonesia 1(1): 5-8.

\section{INTRODUCTION}

Elderly is a time when someone feels satisfied with his success but for others is a period of decline. Elderly is seen as a time of decline, a period of human weakness and a decline in social activity. This view does not specialize in older people who are not homogeneous but there are some who experience it differently. ${ }^{1}$

According to Law of Indonesia Number 13 of 1998 in Chapter 1 Article 2 states of that the age of 60 years is the beginning of the elderly, the aging process does not mean a disease but a gradual process that results in cumulative changes, decreased endurance in facing from inside and outside the body.

The number of older people in Indonesia is increasing every year. In 2007 it is estimated that the number of older people is around 18 million people, in 2015 will experience an increase in the same number as toddlers while in 2020 will be projected with the number of older people will exceed the number of toddlers. In 2025 Indonesia will rank 4 th in the world with an elderly population after the elderly in Republic of China, India and the United States. $^{2}$

A person's lungs will develop continuously with maximum functional status. Lung function will gradually decrease even in athletes who are trying to maintain aerobic capacity during training. Reduction in arterial oxygen level and impaired response due to hypoxia, be aware of aging effect on respiratory function is important to anticipate problems caused by reduced respiratory reserves. $^{2}$

Peak expiratory flows rate is a maximum rate of air achieved during the process of expiration and continued with maximum inspiration. When the elderly is in a healthy state, the process of ventilation will improve so that oxygen demand will increase through the lungs, oxygen can carry out metabolic processes or oxygenation, especially in carbon dioxide in the blood. The filtering process is strengthened by an increase in the exchange of carbon dioxide in the lungs during the respiratory process. $^{3}$

Buteyko breathing exercises are a series of breathing exercises that aim to minimize nasal breathing, holding breath and relaxation, a technique that was developed in 1950 by physiologist Konstantin Pavlovich Buteyko in Russia. ${ }^{4}$

Respiratory muscle stretch gymnastic is designed to stretch the inspiratory muscles of the chest wall during the process of inspiratory breathing and expiratory chest wall muscles during the process of expiratory breathing. Respiratory 
muscle stretch gymnastic is safe for the process of stretching the respiratory muscles in the chest wall during contractions and as an effective method for maintaining respondent's physical activity. ${ }^{5}$

Combination intervention of gymnastic respiratory muscle stretch with buteyko breathing exercises that aim to increase thorax cage mobilization, decreased dyspnea, increased vital capacity of the lungs, suppress expiratory processes that increased expiratory flows and improve the quality of life.
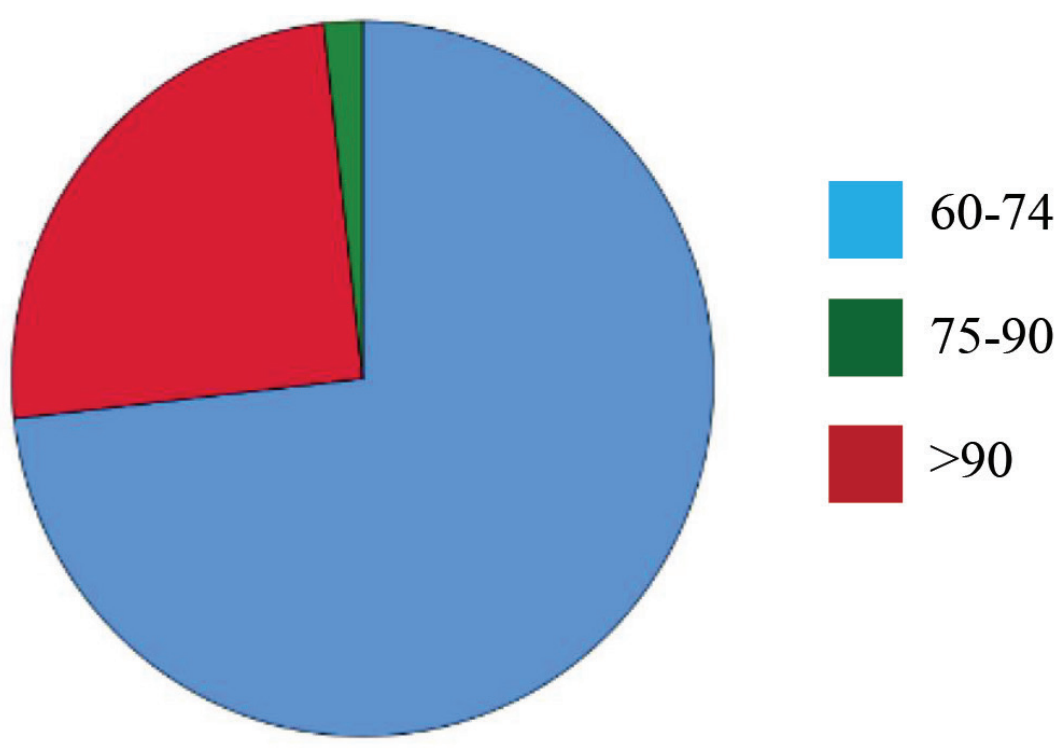

Figure 1. Characteristics of Respondents by age

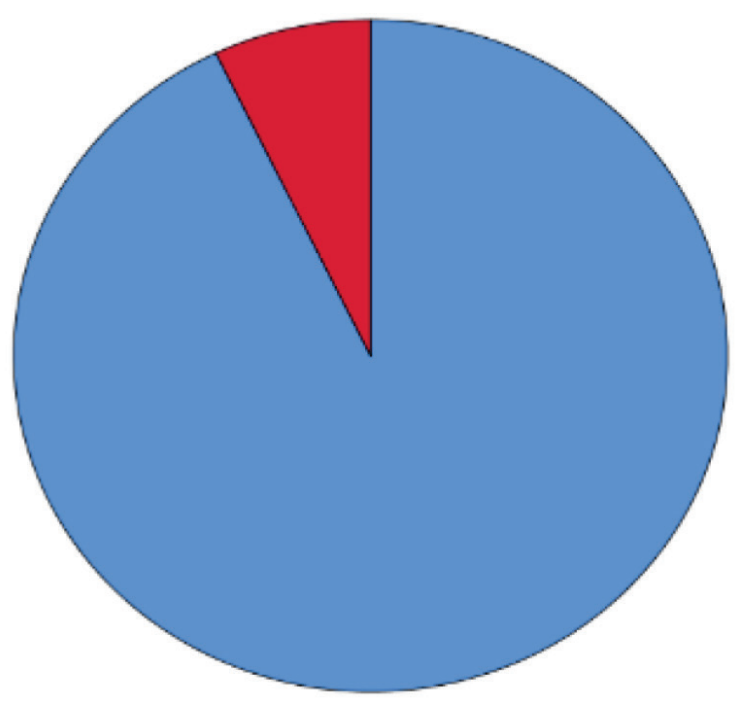

Women

Figure 2. Characteristics of Respondents by Gender

\section{METHODS}

This research method uses an experimental analytical method with a quasi-experimental. The design of this study is used to control external variables that affect implementation during the study, researchers used a quasi-experimental pretest and post-test two groups design. The study was conducted in Sumbersekar Village, Dau Subdistrict, Malang Regency, respondents were taken by purposive sampling with a total sample of 56 samples with an experimental group consisted of 30 samples and a control group consisted of 26 samples.

Data will be tested for normality were analyzed by Kolmogorov-Smirnov because the number of samples more than 50 samples and then analyzing the effect of the research with Wilcoxon Signed Rank Test.

\section{RESULTS}

Changes including the chest wall is one of the abnormalities in the position of the thoracic spine that has begun to decline so that the respiratory system has increased. ${ }^{6}$ Decreased thoracic function of the thoracic spine associated with osteoporosis in the elderly resulting in decreased thoracic cage's ability to expand during the process of inspiration thereby placing the diaphragm to produce effective contractions. Total respiration in adulthood is the same but for chest wall capacity is lower in older samples. In addition, a higher residual volume is associated with a lower chest wall capacity so that it can show obstacles in completing the emptying of the lungs of the rigid chest wall. ${ }^{7}$

Elderly who are more than 60 years old experience a reduction in muscle mass from the diaphragm and accessory muscles in breathing. ${ }^{8}$ Decreased peak expiratory flow in the elderly is caused by degenerative changes in the musculoskeletal system, especially located in the thoracoabdominal, causing a decrease in respiratory muscle strength related to joint movement and lung elasticity. ${ }^{9}$

The mean value of men obtained for peak expiratoryflowishigher than women. Determination of the average value of peak expiratory flow does not depend on age, height or smoking habits. ${ }^{10}$ Not finding a statistically more significant difference in men who have a dependency on smoking and an increase in peak expiratory flow, smoking has a bad effect and should therefore be avoided by the elderly.

Increased risk for various types of lung disease can be caused by smoking which has a negative effect on adulthood, especially in the elderly due to physiological changes. ${ }^{8}$ Smoking actually has 
no effect on the peak flow of female expiration but has a modest effect on peak expiratory flow in men because pulmonary ventilation will show a proportionate increase in the number of cigarettes smoked. The respiratory system will adversely affect the health of individuals especially it can be predicted that there will be a total death. ${ }^{11}$

The difference in expiratory peak flow values is related to body mass index because according to the opinion of Boson and Gardenghi that fat men have higher peak current values than women because accumulation of fat is spread in all parts of the body with dominance located in the abdomen so as to produce interference in ventilator function in larger men. ${ }^{8}$

Improved pulmonary performance can be seen and known in individual activities, especially in individuals who have pulmonary disease that can produce musculoskeletal dysfunction, decondition or skeletal muscle stiffness, systemic inflammation, poor nutritional status, conservation of energy, conditions that can increase mortality or morbidity and can reduce the quality of life, especially in the lives of the elderly. The provision of interventions at various levels many assumes a role in providing basic physical activity practices, but technological advances can therefore lead to a gradual reduction of motor activity in housing, work or recreation. ${ }^{8}$
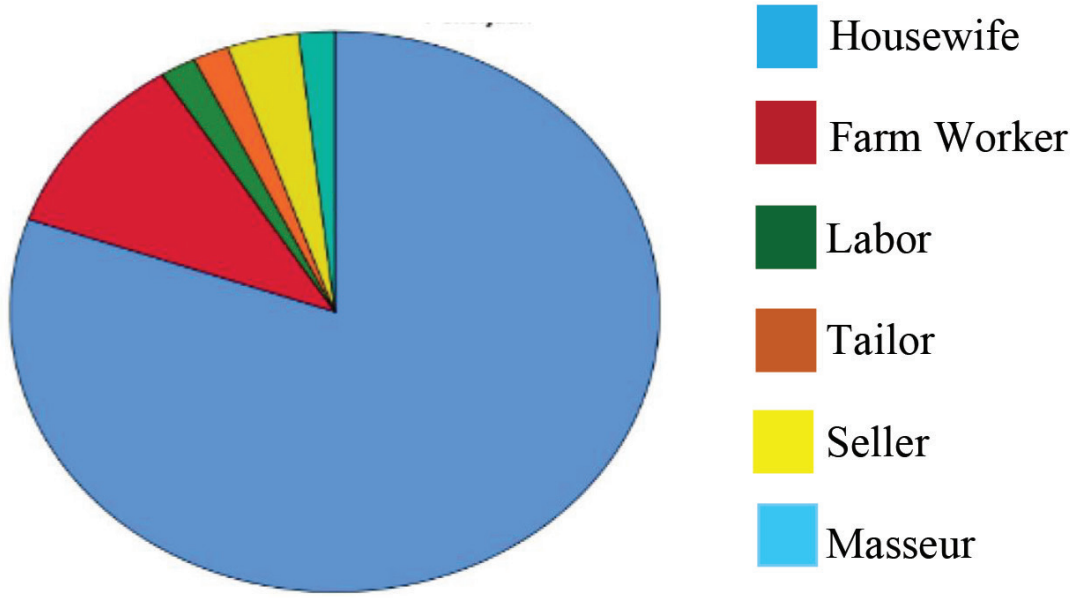

Figure 3. Characteristics of Respondents Based on Employment

Table 1. Wilcoxon Sign Rank Test

\begin{tabular}{ccccc}
\hline Measure & & $\mathbf{n}$ & $\begin{array}{c}\text { Asymp. sig. } \\
\text { (2-tailed) }\end{array}$ & $\mathbf{a}$ \\
\hline $\begin{array}{c}\text { Combination of RMSG with } \\
\text { Buteyko Breathing Exercise }\end{array}$ & Pre-test & 30 & & \\
& Post-test & 30 & & 0.05 \\
\hline
\end{tabular}

\section{DISCUSSION}

Based on the results of gymnastic respiratory muscle stretch and Buteyko breathing exercises obtained a significant value of $0,000(\mathrm{p}<0.05)$ and Sig. (2-tailed) so it can be concluded that $\mathrm{H}_{0}$ is rejected and $\mathrm{H}_{1}$ is accepted. This means that there is an effect of a gymnastic respiratory muscle stretch with buteyko breathing exercises in older population. There is a difference in each expiration peak current value for the experimental group and for the control group during the study before and after treatment.

Peak expiratory flows will experience a significant increase after making gymnastic respiratory muscle stretch movements, the respiratory system can correlate with vital lung capacity because of the reduced process of distensibility of the chest wall as a result can reduce flexor muscle stiffness and the muscles of breathing aids will stretch so that it can reduce stiffness so as to reduce stiffness in the thorax cage. ${ }^{12}$

Buteyko breathing exercise is nonpharmacological interventions that has a function to reduce chronic hyperventilation and help in improving the quality of life. The technique for doing buteyko breathing is breathing by controlling slowly and shallow and during the process of breathing must be a gentle rhythm and can be felt by the subject during the process of inspiration and expiration. Buteyko breathing exercises are carried out for 20-30 minutes twice a day for 3 weeks so that respondents can actively gain control of breathing patterns. ${ }^{13}$

\section{CONCLUSION}

Based on results of the research that has been done, it can be concluded that there is an effect of a gymnastic respiratory muscle stretch exercises and buteyko breathing exercises to increase the peak expiratory flows.

\section{CONFLICT OF INTEREST}

No commercial party having an interest in this study and no any benefit was received by the authors or authors' affiliations.

\section{ACKNOWLEDGEMENT}

The authors want to thank all the headman of Sumbersekar Village, Dau Subdistrict, Malang Regency, Indonesia for giving permission and information during this study period. The author received no funding from any institution for this study. 


\section{AUTHOR CONTRIBUTIONS}

$\mathrm{MH}$ carried out the study design, data collection, and drafting the article; AM conceived the study design, data interpretation, and drafting the article.

\section{REFERENCES:}

1. Wijayanti. 2008. Hubungan Kondisi Fisik Rtt Lansia Terhadap Kondisi Sosial Lansia di RW 03 RT 05 Kelurahan Tegalsari, Kecamatan Candisari. Jurnal Ilmiah Perancangan Kota dan Pemukiman. 7 (1)

2. Nugroho (2008). Keperawatan Gerontik. Buku Kedokteran EGC: Jakarta.

3. Malhotra, Varun., N, Srinivasaragavan., Patil, Rajkumar., R, Jaiganga. 2011. Correlation of Peak Expiratory Flow Rate with Anthropometric Parameters in Young Adults. International Journal of Current Research and Review. 3 (11)

4. Cowie, L. Robert., Conley, P. Diane., Underwood, F. Margot., Reader, D. Patricia. 2008. A Randomised Controlled Trial of the Buteyko Technique as an adjunct to conventional management of asthma. Calgary; Elsevier

5. Toyodera, Mai., Yuri, Masaoka., Akai, Lena., Hanaoka, Kentaro., Ono, Shinichiro., Izumizaki, Masahiko., Itahashi, Kazuo., Homma, Ikuo. 2013. Effects of Respiratory Muscle Gymnastic on Children's Emotional Respones. Journal Medical Science. 25 (3)

6. Fragos, carlor. 2011. Respiratory impairtment and the aging lung: $A$ novel paradigm for assessing pulmonary function. America; Oxford university press on behalf of the gerontology society.

7. Sharma, Gulshan., Goodwin, James. 2006. Effect of Aging on Respiratory System Physiology and Immunology. Clinical Interventions in Aging. 1 (3)
8. de Andrade AD, Júnior JC, Lins de Barros Melo TL, Rattes Lima CS, Brandão DC, de Melo Barcelar J. 2014. Influence of different levels of immersion in water on the pulmonary function and respiratory muscle pressure in healthy individuals: observational study. Physiother Res Int;19:140-146.

9. Sandhu, Perminder. Kaur., Bajaj, Dimpel., Mehta, Kiran. 2016. Correlation of Peak Expiratory Flow Rate with Age and Anthropometric Parameters in Elderly ( $>65$ years). National Journal of Physiology, Pharmacy, Pharmacology. 6 (1)

10. Boezen, H.M., Schouten, J.P., Postma, D.S., Rijcken, B. 1994. Distribution of Peak Expiratory Flow Variability by Age, Gender and Smoking Habits in A Random Population Sample Age 20-70 Years. European Respiratory Journal. Vol. 7

11. Srinivas, P., Chia, Y.P., Poi, P.J.H., Ebrahim, Shah. 2014. Peak Expiratory Flow Rate in Elderly Malaysians. Medical Journal Malaysia. 54 (1)

12. R, Sitalakshmi., N, Poornima. K., N, Karthick. 2013. The Peak Expiratory Flow Rate (PEFR): The Effect of Stress in a Geriatric Population of Chennai- A Pilot Study. Journal of Clinical an Diagnostic Research. 7 (2)

13. Karpagam., P, Mangalagowri., S, Aruna. 2017. Effectiveness of Buteyko Breathing Technique on Level of Peak Expiratory Flow Rate and Asthma Symptoms Among Patients with Bronchial Asthma. International Journal of Pharma and Bio Sciences 8 (3)

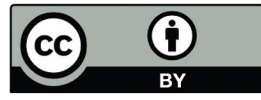

This work is licensed under a Creative Commons Attribution 